\title{
An assessment of the potential impact of climate change on flood risk in Mumbai
}

\author{
Nicola Ranger • Stéphane Hallegatte · Sumana Bhattacharya • Murthy Bachu • \\ Satya Priya · K. Dhore · Farhat Rafique $\cdot$ P. Mathur • Nicolas Naville • \\ Fanny Henriet • Celine Herweijer • Sanjib Pohit • Jan Corfee-Morlot
}

Received: 28 July 2009 / Accepted: 6 July 2010 / Published online: 7 December 2010

(C) Springer Science+Business Media B.V. 2010

\begin{abstract}
Managing risks from extreme events will be a crucial component of climate change adaptation. In this study, we demonstrate an approach to assess future risks and quantify the benefits of adaptation options at a city-scale, with application to flood risk in Mumbai. In 2005, Mumbai experienced unprecedented flooding, causing direct economic damages estimated at almost two billion USD and 500 fatalities. Our findings suggest that by the 2080s, in a SRES A2 scenario, an 'upper bound' climate
\end{abstract}

\section{N. Ranger $(\bowtie)$}

The Grantham Research Institute on Climate Change and the Environment, London School of Economics and Political Science, Houghton Street, London, WC2A 2AE, UK

e-mail: n.ranger@1se.ac.uk

URL: http://www.lse.ac.uk/grantham

N. Ranger

Risk Management Solutions Ltd., London, UK

S. Hallegatte $\cdot$ N. Naville $\cdot$ F. Henriet

Centre International de Recherche sur l'Environnement et le Développement, Paris, France

S. Hallegatte

Ecole Nationale de la Météorologie, Météo-France, Toulouse, France

S. Bhattacharya

NATCOM PMC, MoEF, Chennai, India

M. Bachu $\cdot$ S. Priya $\cdot$ K. Dhore $\cdot$ F. Rafique $\cdot$ P. Mathur

RMS India, Hyderabad, India

C. Herweijer

PriceWaterhouseCoopers, London, UK

S. Pohit

National Council of Applied Economic Research, Hyderabad, India

J. Corfee-Morlot

Organisation for Economic Co-operation and Development, Paris, France 
scenario could see the likelihood of a 2005-like event more than double. We estimate that total losses (direct plus indirect) associated with a 1-in-100 year event could triple compared with current situation (to \$690-\$1,890 million USD), due to climate change alone. Continued rapid urbanisation could further increase the risk level. The analysis also demonstrates that adaptation could significantly reduce future losses; for example, estimates suggest that by improving the drainage system in Mumbai, losses associated with a 1-in-100 year flood event today could be reduced by as much as $70 \%$. We show that assessing the indirect costs of extreme events is an important component of an adaptation assessment, both in ensuring the analysis captures the full economic benefits of adaptation and also identifying options that can help to manage indirect risks of disasters. For example, we show that by extending insurance to $100 \%$ penetration, the indirect effects of flooding could be almost halved. We conclude that, while this study explores only the upper-bound climate scenario, the risk-assessment core demonstrated in this study could form an important quantitative tool in developing city-scale adaptation strategies. We provide a discussion of sources of uncertainty and risk-based tools could be linked with decision-making approaches to inform adaptation plans that are robust to climate change.

\section{Introduction}

Many of the world's cities are hotspots of risk from extreme weather events (e.g. Munich Re 2004) and levels of risk in many cities are likely to grow due to a combination of population growth and development and rising intensities of extreme weather events. For example, Hanson et al. (2011, in this issue) demonstrate high population and economic exposure to storm surge risks in many of the world's largest and fastest growing cities. These are also areas where adaptation can have significant benefits. Managing risks from extremes will be a crucial component of adaptation planning.

A challenge in planning adaptation relates to the quantification of the risks from extreme weather events and the benefits of different adaptation measures. This study presents an approach to quantifying city-scale risks that is based on Hallegatte et al. (2011a, in this issue); here it draws on the principles of catastrophe risk modelling commonly used in the developed world but simplified for application for a more data sparse region and coupled with downscaled climate model projections. This approach is applied to quantifying future flood risk in the city of Mumbai, India. Mumbai is the main commercial and financial centre of India, generating about $5 \%$ of India's gross domestic product (GDP). The study also aims to demonstrate the importance of capturing the indirect costs of disasters in risk and adaptation assessments.

The study follows the broad stages of an 'impacts-based' adaptation assessment (Carter et al. 2007): firstly, characterising current levels of vulnerability and potential future sensitivities (Section 2); secondly, quantifying relevant risks (Sections 3 and 4); and thirdly, identifying adaptation options and evaluating their benefits (Section 5). This study does not complete the adaptation assessment, it only aims to demonstrate various elements; for example, it is limited in that it explores one ('upper-bound') climate scenario and it looks at a limited set of adaptation options (and only benefits, not costs). It also does not enter the next stage of applying decision methods and forming strategies; though in Section 6 we provide a brief discussion of our approach in this context. We note that this study is part of an ongoing body of research 
sponsored by the OECD; forthcoming research over the next year will expand on this study with additional research from a number of local partners.

\section{Mumbai: current vulnerability to flooding and future sensitivities}

A logical first stage of any adaptation assessment is to understand levels of current vulnerability to weather. Mumbai is prone to flooding and witnesses severe disruptions almost annually; for example, between 2004 and 2007, Mumbai experienced flooding each summer. But in July 2005, the city experienced the worst flooding in its recorded history, resulting in damages estimated at around $\$ 1.7$ billions USD and around 500 fatalities (GoM 2005). Across Northwest India, the flooding crippled an area of over $35,500 \mathrm{~km}^{2}$, affecting 20 million people and causing economic damages of around \$3-5 billions US (Swiss Re 2006; Munich Re 2006). Figure 1 shows a map of the flood extent across the City and Suburban districts of Mumbai (which collectively

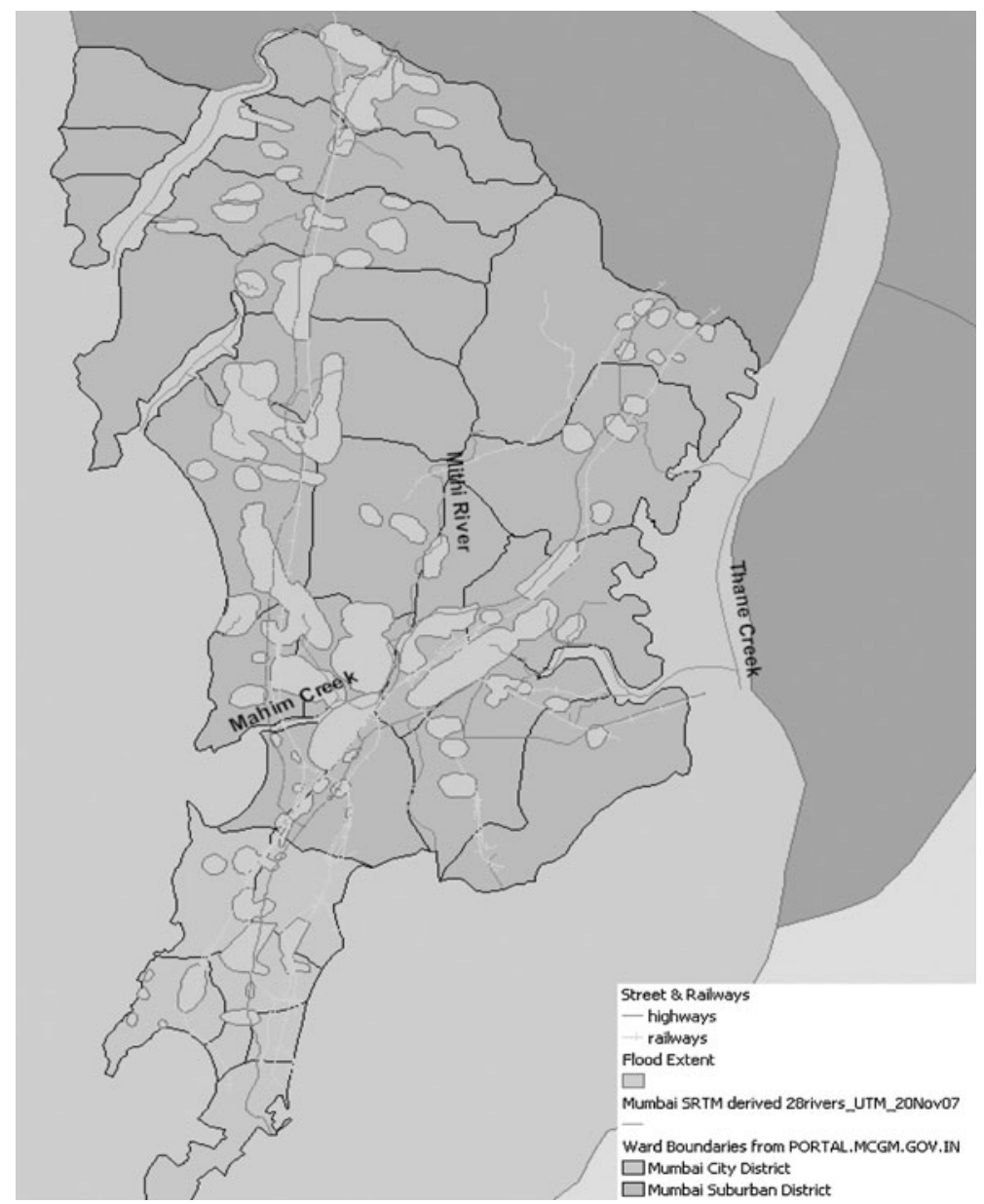

Fig. 1 Digitized flood extent map for the 2005 event (based on Gupta 2007), showing the city wards and the location of the Mumbai City and Suburban Districts 
form the Greater Mumbai region) digitalised from Gupta (2007); around 20\% of the area was affected, with flood waters to a depth of 0.5 to $1.5 \mathrm{~m}$ in low-lying areas.

The root cause of Mumbai's susceptibility to flooding is its geography, both natural and manmade (Duryog Nivaran 2005). Firstly, the city's location leaves it exposed to heavy rainfall during the summer; typically, $50 \%$ of the rainfall during the two wettest months, July and August, falls in just two or three events (Jenamani 2006). This situation is aggravated by the manmade geography; large areas of the land are reclaimed and are situated only just above sea level and below the high-tide level. This inhibits natural runoff of surface water and the complicated network of drains, rivers, creeks and ponds drain directly in the sea, meaning that during high tides, sea water can enter the system preventing drainage and in extreme cases, leading to salt water deluge. This occurred during the July 2005 event; a massive inundation of the drainage systems caused as almost $1000 \mathrm{~mm}$ of rainfall fell on the city in $24 \mathrm{~h}$ was combined with a failure of the system as sea water entered during high tide.

Future levels of flood risk are also potentially sensitivity to climate change and other drivers of risk. Urbanisation has been an important driver of increased flood risk in the city. For example, it is estimated that urbanisation alone has contributed to a two or three fold increase in runoff in the city. The drainage systems of the city are now inadequate to cope with heavy rainfall and are impeded by urban encroachment and channel blockages. Continued rapid urbanisation, particularly in the absence of effective spatial planning and improved drainage systems, is likely to lead to an increase in flood risk in Mumbai.

Over the coming decades, the pressures of urbanisation may be aggravated by manmade climate change. Like many other areas, the Northwest of India has observed a statistically significant warming of annual mean surface air temperatures over the past century (IPCC 2007, Figure 3.9). While no statistically significant trend in annual rainfall has been observed in the past three decades (IPCC 2007, e.g. Figure $3.13)$, there are signs of an increased contribution to annual rainfall from very wet days (Alexander et al. 2006). In the future, an increase in rainfall volume and/or intensity could increase the risk of severe flooding. Global climate models (GCMs) give a divergent picture of how precipitation will change in Northwest India over this century. For example, the ensemble mean of the GCM projections assessed in IPCC (2007) suggests a small average increase in the summer precipitation (roughly $5 \%$ of 1990 levels by the 2090s), however this small average masks large positive and negative changes projected by individual models. The strong uncertainty in this region is driven by the inability of the current generation of GCMs to adequately represent the detailed topography of South Asia and the cloud microphysics involved in tropical convective processes.

\section{Quantifying current and future flood risk in Mumbai}

The risk quantification approach used in this study follows a standard catastrophe risk modelling framework, which combines estimates of hazard, exposure and vulnerability (Grossi and Kunreuther 2005). This framework provides an estimate of the direct economic damages and population exposed to flood events with different probabilities of occurrence. In this study, probabilities are represented as return periods of events, i.e. a 1 in 200 year return period (denoted yr RP) event has a $0.005 \%$ annual probability of occurrence. To this framework we add an additional 
component (Section 4) that estimates the indirect damages from flood events. To inform adaptation decision-making it is also important to consider fatalities or injuries, but this is beyond the scope of this study. In this analysis, we explore only the effect of changes in rainfall on levels of risk. Without effective adaptation, continued rapid urbanisation and sea level rise would combine with rainfall changes to further increase levels of risk.

\subsection{Hazard quantification}

This sub-section describes the approach to quantify the current and future frequencies of heavy rainfall events for Mumbai and the generation of simulated flood footprints. There are two key challenges in quantifying flood hazard: the short length of available rainfall records for the city and the inadequacies of climate models in projecting changes in rainfall at a city-scale (IPCC 2007).

Rainfall observations are taken from the Santa Cruz Indian Meteorological Department (IMD) station located in the Mumbai Suburban District (closest to the most extreme flooding). This 30-year record is extended empirically using the WXGEN weather generator (Williams et al. 1985; Sharpley and Williams 1990a, b; Wallis and Griffiths 1995) to create a 200-year simulated record. The simulation is based on six key statistical characteristics of the timeseries analysed from the historical data. ${ }^{1}$ A further challenge highlighted by the analysis is that the rainfall that led to the 2005 flooding far exceeded any daily amount measured since records began; in the $24 \mathrm{~h}$ starting at 8:30am on 26th July 2005, $944 \mathrm{~mm}$ of rainfall was measured at Santa Cruz. Including such an outlier in an analysis based on a short rainfall timeseries has the potential to skew the findings of the study. For this reason, two simulated time series were constructed, one including the July 2005 event in the statistical analysis (denoted Hist_SZ_I) and one disregarding it (Hist_SZ_X). Return periods of daily maximum rainfall for Santa Cruz are estimated by fitting a simple lognormal distribution to the 200-year time series (Fig. 2). The analysis suggests that the event that led to the 2005 flooding had a return period of at least around 150 years, and possibly much greater than 200 years. It is not possible to pinpoint the frequency with greater accuracy given the short-length of the available rainfall record. We assume that the return period of a 2005-like event will lie between our two estimates (from Hist_SZ_X and Hist_SZ_I); that is, around 1 in 200 years.

Future precipitation projections for the 2080s are taken from the PRECIS model (Jones et al. 2004); a high resolution regional climate model based on HadCM3. The 2080s timescale is selected as this is relevant to many long-term infrastructure and building decisions being taken today. PRECIS is selected as Kumar et al. (2006) notes that only the HadCM3 and CSIRO models are able to adequately represent present-day rainfall extremes in western India and PRECIS is shown to provide a good representation of the spatial patterns of relevant seasonal rainfall and extremes. However, the HadCM3 seasonal mean rainfall projections are at the upper bound of estimates across the IPCC model ensemble (IPCC 2007); in fact, only slightly over half of the 21 models assessed project an increase in precipitation over Northwest

\footnotetext{
${ }^{1}$ The average rainfall, standard deviation, skew coefficient, probability of wet day followed by dry day, probability of wet day followed by wet day and the number of rainy days.
} 
Fig. 2 Estimates of the return period of daily maximum rainfall at Santa Cruz historically and in the 2080s (under a high-end scenario). Further details on each estimate shown are given in the text, where (1) 2080s Projection is denoted A2_SZ_X; (2) Historical, including 2005 is denoted Hist_SZ_I; and (3) Historical, excluding 2005 is denoted Hist_SZ_X. Note that A2_SZ_X is comparable to Hist_SZ_X

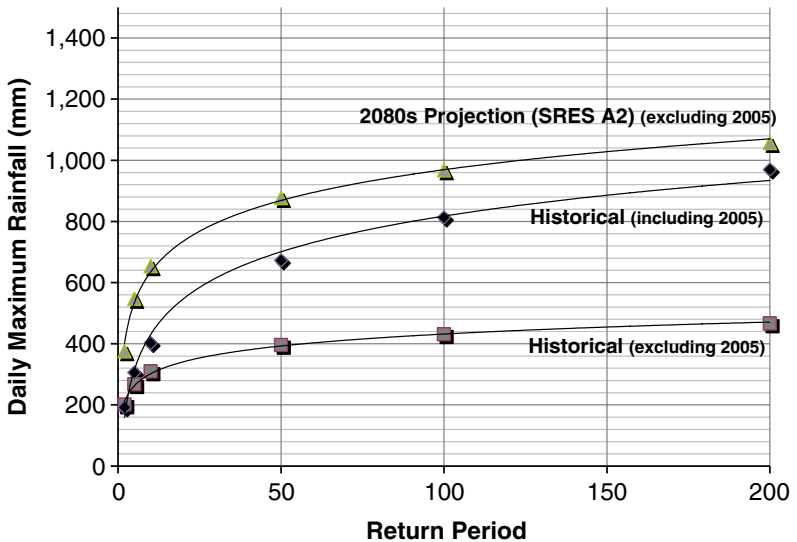

India. The model is driven with the A2 SRES emissions scenario (Nakicenovic et al. $2000)$. Under this scenario, PRECIS projects a $3.6^{\circ} \mathrm{C}$ increase in mean temperatures a $6.5 \%$ increase in seasonal mean rainfall across India by the 2080s. Given the uncertainties in climate, a full adaptation assessment would explore the implications of a range of model-based climate scenarios; this is beyond the scope of this study. The findings of this study alone could be considered indicative of an upper-end estimate of possible future risks; we would not consider this a 'worst-case' estimate as it is not clear that the range of current climate model projections fully represent the range of uncertainties. Our interpretation is that given current understanding, this is one of a set of equally probable scenarios.

The PRECIS results are first downscaled and extended using WXGEN to create a 200-year rainfall timeseries comparable to the simulated records for the Santa Cruz station. The downscaling involves mapping the change in the statistical characteristics of rainfall between the Baseline (1961-1990) and 2080s Projected (20712100) precipitation in the PRECIS model for the relevant grid box. These statistical characteristics are the same six characteristics used to drive WXGEN. These changes are then mapped as linear multipliers onto the statistical characteristics analysed at Santa Cruz (Hist_SZ_X) to estimate future statistical characteristics at the location. The final step is to run WXGEN with these 'future characteristics' to generate the new 2080s time series (A2_SZ_X). This procedure assumes that the statistical relationships between the large-scale (the PRECIS baseline) and small-scale (Santa Cruz) timeseries remain unchanged such that it is appropriate to map 'future' statistical characteristics between each. This assumption is untested and therefore introduces uncertainty into the findings.

Figure 2 demonstrates that by the 2080s, the intensity of extreme rainfall could be increased at all return periods. The increase is particularly strong for the shorter return period (more frequent) events. For example, under this scenario, the intensity of a 2-5 year return period event has close to doubled. The analysis suggests that the return period of an event of July 2005 scale is reduced to around 1-in-90 years

Fig. 3 a Fifty-year return period flood maps for present day (left) and 2080s (right). b One-hundredyear return period flood maps for present day (left) and 2080s (right). c Two-hundred-year return period flood maps for present day (left) and 2080s (right) 


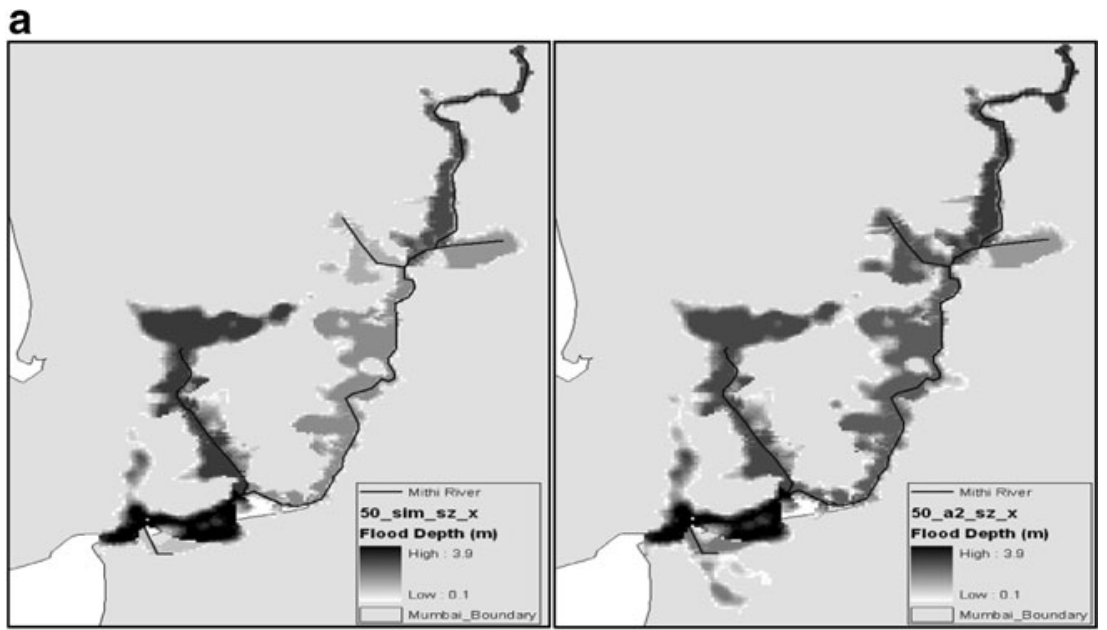

b

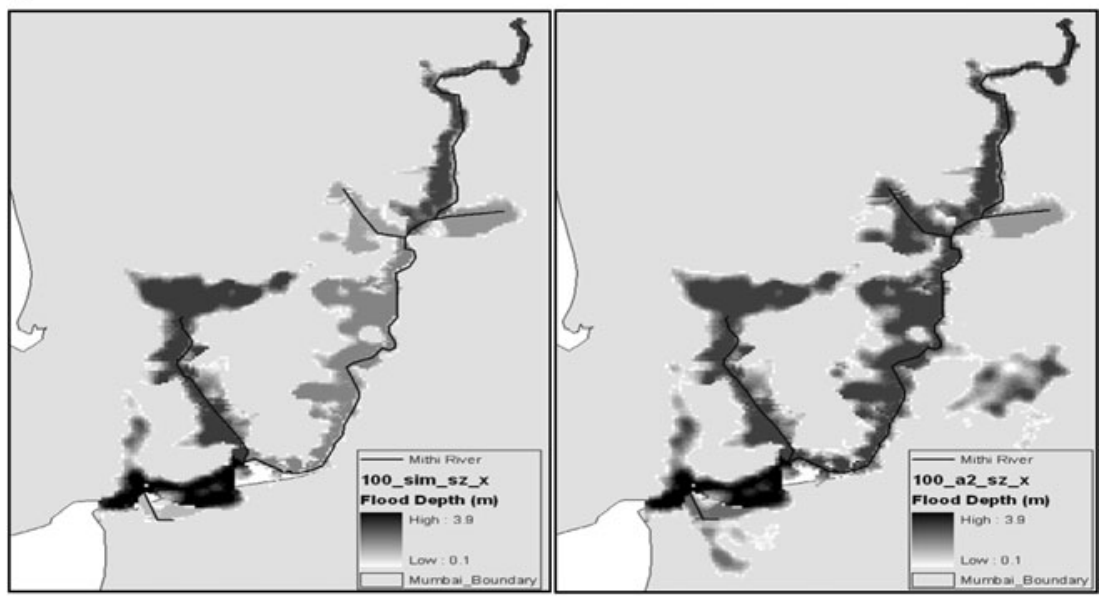

C

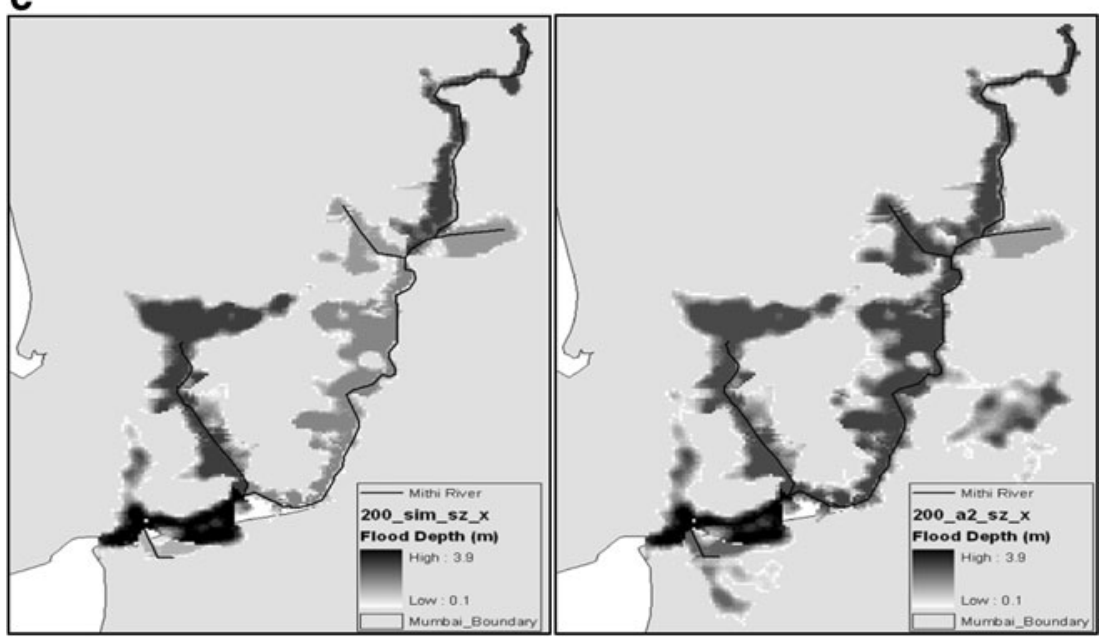


in 2080 under a SRES A2 scenario. Even though this analysis has several limitations and is based on only one climate model, this result shows a high potential sensitivity of flood risk to climate change and provides a justification for further investigation.

Given that urban flooding in Mumbai is mainly pluvial, we would expect an increase in the frequency of extreme rainfall to translate into an increase in flood hazard (all else being equal). Rivers in Mumbai tend to act as open drains during extreme rainfall events, carrying excess surface water to the sea and major flooding can occur when the rainfall rates exceeds the drainage capacity of these rivers. Here, we use an urban flood model to simulate the relationship between rainfall and flood extents. There are three main river basins in the study area; here, we focus on Mithi River Basin, where some of the greatest flood damages occurred in 2005, and extrapolate to city-scale in later sections. The Mithi basin is directly fed by the rainfall observed at the Santa Cruz station. The modelling approach uses the Storm Water Management Model (SWMM), modified to represent the Mithi Basin (for details, see Appendix A), to generate hypothetical flood footprints which correspond to the 2005 event and for the simulated rainfall events with the return periods of 50, 100 and 200 years, for today (Hist_SZ_X) and in the 2080s (A2_SZ_X). Figure 3 shows the estimated flood extents and depths for these simulated events. With climate change, we see an extension of the area flooded at each return period and an increase in flood depth. A limitation of this analysis is that it does not take into account the potential effect of sea level rise in reducing the effectiveness of the drainage systems.

Applied to the 2005 flood event, we find that the SWMM model underestimates the observed flood extent by around $20 \%$, likely due to the low resolution of the elevation data used. This relationship can be used to calibrate the simulated returnperiod flood footprints. Table 1 shows the uncalibrated area of the Mithi Basin flooded for each simulated event.

\subsection{Exposure mapping}

An exposure map shows the spatial distribution of all the people or properties in the study area. This is compared with the flood footprint to estimate the affected exposure'. We assume an unchanged city (i.e. population and properties at their mid2000 s values). Population and growth factors can be applied to this to estimate future exposure.

A digitalised population map was developed from publicly available 2001 census data (MCGM 2008). The data, at ward-level, was distributed evenly over a $100 \mathrm{~m}$ grid. The distribution of residential, commercial and industrial property types was derived by analysing observations from the IRS LISS III satellite (Indian Remote Sensing Satellite, Linear Image Self Scanning III) fused with a panchromatic image

Table 1 Comparison of (uncalibrated) flood extent areas under different simulated rainfall scenarios (A2_SZ_X) for the Mithi Basin generated by the SWMM model

\begin{tabular}{lll}
\hline Simulated event ID & Today & $2080 \mathrm{~s}$ \\
\hline 2005 event & 16 & - \\
50 years RP event & 12 & 14 \\
100 years RP Event & 12 & 16 \\
200 years RP Event & 12 & 17 \\
\hline
\end{tabular}


at a resolution of $10 \mathrm{~m}$. Six exposure types were defined: two residential (low density and high density), three commercial (low-rise retail and offices, high-rise office blocks and skyscrapers) and one industrial. The total insured values (TIVs) of these properties were based on the RMS India Earthquake Model ${ }^{\circledR}$ (INEQ), which incorporates proprietary insurance data. This data is distributed onto the $100 \mathrm{~m}$ grid according to the exposure types. Across the two study districts, we estimated a TIV of $\$ 480$ million USD, $\$ 520$ million USD and \$1,960 million USD for the residential, commercial and industrial exposures, respectively. The TIV can be converted to a total value if the insurance penetration is known. Here, the insurance penetration is assumed to be roughly around $8 \%$ for residential properties, $14 \%$ for commercial properties and $17 \%$ for industrial properties, based on RMS proprietary data. Note that these estimates have a high uncertainty and that the exposure estimates are highly sensitive to this quantity.

Combining the exposure maps with the observed flood footprint from the 2005 flooding (Fig. 1), it is possible to calculate the 'affected exposure' across Greater Mumbai in 2005 (Table 2). This demonstrates, for example, that $35 \%$ of the resident population lived in areas directed affected by the flooding.

Table 3 uses the same methodology but with the simulated flood footprints for the Mithi River Basin (Fig. 3), giving estimates of the affected exposure at different return periods in that area of the city.

We can extrapolate from these Mithi affected exposure estimates to create 'ballpark' estimates of the affected exposure across the whole of the Greater Mumbai area (Table 4), using the relationship between the observed affected exposure across these districts for July 2005 (from Table 2) and the simulated affected exposure in the Mithi Basin (from Table 3). The uncertainty introduced by this extrapolation is large, for example, it assumes that the relationship between Mithi and Mumbai flooding remains the same for all flood events.

\subsection{Estimating vulnerability}

Vulnerability here refers to the damage cost to a property expected for a given level of water depth. This is expressed in terms of the mean damage ratio; that is, the monetary damage as a proportion of the total value of affected property. Usually in risk modelling, vulnerability is defined by a set of 'damage curves'. However, because of the lack of reliable data on building vulnerability in Mumbai, and to provide preliminary estimates, we define only an average mean damage ratio for an affected residential, commercial or industrial property type (i.e. three ratios). A consequence of using a mean damage ratio instead of a vulnerability curve is that only the change in flood extent is taken into account and the change in flood depth is not in spite of

Table 2 A comparison of total exposure over the Greater Mumbai area to the affected exposure for the July 2005 flood event (using population data for 2001 and the observed flood footprint)

\begin{tabular}{lcllllr}
\hline & Area & Population & \multicolumn{5}{l}{ Exposure (in \$ million USD) } \\
\cline { 5 - 7 } & $\left(\mathrm{km}^{2}\right)$ & (thousands) & Residential & Commercial & Industrial & Total \\
\hline Total & 372 & 12,800 & 6,000 & 3,710 & 11,530 & 21,240 \\
Affected & 78 & 4,200 & 1,880 & 1,070 & 2,110 & 5,060 \\
Percentage affected & $20 \%$ & $35 \%$ & $30 \%$ & $30 \%$ & $20 \%$ & $20 \%$ \\
\hline
\end{tabular}


Table 3 Modelled 'affected' exposures for different return period flood events for the Mithi Basin, in comparison to the simulated July 2005 event

\begin{tabular}{|c|c|c|c|c|c|}
\hline & \multirow{2}{*}{$\begin{array}{l}\text { Area } \\
\left(\mathrm{km}^{2}\right)\end{array}$} & \multirow{2}{*}{$\begin{array}{l}\text { Population affected } \\
\text { (thousands) }\end{array}$} & \multicolumn{3}{|c|}{ Affected exposure Mithi Basin (\$ million USD) } \\
\hline & & & Residential & Commercial & Industrial \\
\hline Simulated 2005 & 16 & 1,220 & 375 & 180 & 590 \\
\hline 50 years RP: present & 12 & 710 & 250 & 70 & 0 \\
\hline 50 years RP: future & 14 & 975 & 315 & 145 & 0 \\
\hline 100 years RP: present & 12 & 710 & 250 & 105 & 0 \\
\hline 100 years RP: future & 16 & 1,225 & 375 & 180 & 560 \\
\hline 200 years RP: present & 12 & 715 & 250 & 105 & 0 \\
\hline 200 years RP: future & 17 & 1,275 & 375 & 180 & 590 \\
\hline
\end{tabular}

its potential importance. For example, in Fig. 3c, one can see that in the 2080s, floods are expected to become larger and deeper than today. The estimate of how flood losses will change is therefore underestimated compared with a more comprehensive analysis.

The average mean damage ratio that is used here is estimated based on published estimates of damages from the July 2005 event. While it would be preferable to use multiple events, this data was not available. The data available for 2005 was also very limited; for this reason, three approaches were used to estimate the vulnerability, then the results compared to produce a single estimate with an uncertainty range. The three approaches used were:

- Using published economic loss estimates: The mean damage ratio was given by the ratio of the direct economic loss to affected exposure for the July 2005 event. Estimates of residential damages (GoM 2005) were used directly to estimate the residential mean damage ratio. The commercial and industrial economic damages were derived from the total economic damage, using the proportions indicated by their affected exposures. The total direct economic losses at state level were obtained from the Dartmouth Flood Observatory (2008) and Swiss Re (2006); we assume that $50 \%$ of these damages occurred in the Greater Mumbai

Table 4 Estimated affected exposures for different return period flood events

\begin{tabular}{llllll}
\hline & $\begin{array}{l}\text { Area } \\
\left(\mathrm{km}^{2}\right)\end{array}$ & $\begin{array}{l}\text { Population } \\
\text { (thousands) }\end{array}$ & \multicolumn{2}{l}{$\begin{array}{l}\text { Affected exposure across the Mumbai City } \\
\text { and suburban districts (\$ million USD) }\end{array}$} \\
\cline { 5 - 6 } & & & Residential & Commercial & Industrial \\
\hline Simulated July 2005 & 78 & 4,270 & 1,875 & 1,070 & 2,120 \\
50 years RP: present & 55 & 2,470 & 1,250 & 430 & 0.0 \\
50 years RP: future & 67 & 3,400 & 1,565 & 860 & 0.0 \\
100 years RP: present & 56 & 2,470 & 1,250 & 645 & 0.0 \\
100 year RP: future & 78 & 4,270 & 1,875 & 1,070 & 2,010 \\
200 year RP: present & 57 & 2,490 & 1,250 & 645 & 0.0 \\
200 year RP: future & 80 & 4,440 & 1,875 & 1,070 & 2,120 \\
\hline
\end{tabular}


Table 5 Estimated direct total economic losses for different return period flood events for Mumbai, excluding infrastructure

\begin{tabular}{lccll}
\hline & \multicolumn{3}{c}{ Estimated direct losses [excluding infrastructure] (\$ million USD) } \\
\cline { 2 - 5 } & Residential & Commercial & Industrial & Total \\
\hline Simulated July 2005 & $100-300$ & $170-400$ & $220-660$ & $490-1,370$ \\
50 years RP: present & $70-210$ & $80-190$ & 0 & $150-400$ \\
50 years RP: future & $90-260$ & $120-290$ & 0 & $210-550$ \\
100 years RP: present & $70-210$ & $90-220$ & 0 & $160-430$ \\
100 years RP: future & $100-310$ & $180-420$ & $200-630$ & $490-1,350$ \\
200 years RP: present & $70-210$ & $90-220$ & 0 & $160-430$ \\
200 years RP: future & $110-320$ & $180-430$ & $220-680$ & $510-1,420$ \\
\hline
\end{tabular}

$\operatorname{area}^{2}$ and that around $70 \%$ of these losses were related to residential, commercial and industrial damages (extracting infrastructure as given in Hallegatte et al. (2011b), in this issue), giving total losses of 1.7 billion USD.

- Using insured loss estimates: Here, the mean damage ratio was given by the ratio of the insured loss (from RMS insurance claims data) to affected insured exposure (from the RMS INEQ model) for the July 2005 event. The benefit of this approach is that these estimates are more widely available and they require no assumption about insurance penetration.

- Using RMS proprietary vulnerability curves: Simplified flood vulnerability curves for a generic industrial, commercial or residential facility were combined with estimates of flood depth across the Mumbai City and Suburban Districts (obtained from media reports) to derive a mean damage ratio. The mean flood depths were assumed to be around $0.1-0.25 \mathrm{~m}$ in Mumbai City and $0.25-0.5 \mathrm{~m}$ in the Suburbs based on Gupta (2007) and local media reports.

Drawing together the results from each of these approaches, we estimate an average mean damage ratio of: $5-15 \%$ for residential properties; $15-35 \%$ for commercial properties; and $10-30 \%$ for industrial properties. These ranges are relatively narrow, giving confidence in the individual estimation approaches.

\subsection{Direct damage estimates for Mumbai}

The direct damage costs are defined as the costs of repairing or replacing assets that have been damaged or destroyed (at the pre-event price level). Table 5 gives estimates of the direct damages from flooding in Mumbai for different return period rainfall events. This is calculated by applying the average mean damage ratios (derived above) to the affected exposure estimates (from Table 4). The ranges reflect the uncertainty in vulnerability. Table 6 gives an estimate of the total direct losses including infrastructure losses; where these losses are assumed to be around $40 \%$ of

${ }^{2}$ Estimated based GoM 2005, e.g. Greater Mumbai accounted for slightly over half of the total residential property losses. 
Table 6 Estimated total direct losses for different return period flood events for Mumbai including infrastructure losses

\begin{tabular}{lll}
\hline & \multicolumn{2}{l}{$\begin{array}{l}\text { Estimated total direct losses (including } \\
\text { infrastructure) \$ million USD }\end{array}$} \\
\cline { 2 - 3 } & Present-day & 2080s \\
\hline Simulated July 2005 & $690-1910$ & - \\
50 years RP & $210-570$ & $290-760$ \\
100 years RP & $230-600$ & $690-1890$ \\
200 years RP & $230-600$ & $720-1990$ \\
\hline
\end{tabular}

the total value of residential, commercial and industrial losses (see Hallegatte et al. $2011 b$ in this issue). The loss estimates for the July 2005 event (\$690-\$1910 million USD) are roughly in line with the $\$ 1.7$ billion losses estimated above.

The results suggest that losses associated with a 1-in-50 year extreme rainfall event could rise by $35 \%$, but losses associated with a 1-in- 100 year event could rise by $200 \%$ (i.e. triple) and for a 1 -in-200 year event, losses could rise by up to $230 \%$.

It should be noted that this study's estimates of future costs do not take into account population and economic growth. In reality, the Indian urbanization rate and economic production are increasing very rapidly and this is likely to continue to increase flood risk in Mumbai in the absence of adaptation. For instance, the population of the Mumbai Metropolitan Region increased from 13 to 17 million inhabitants from 1991 to 2008. In 2025, it has even been estimated that the Mumbai population might increase to up to 28 million inhabitants (Regional Plan for Mumbai Metropolitan Region 1996-2011, by the Mumbai Metropolitan Region Development authority). This will not only increase the exposure to flooding, but also put further strain on the natural and manmade drainage systems if improvements are not implemented, potentially increasing hazard and risk levels. In addition, without improvements to the drainage systems, sea level rise will reduce their effectiveness and further increase hazard and risk levels.

\section{Evaluating the total economic impacts of flooding}

Direct losses, the costs of replacing and reconstructing damaged buildings and infrastructure, account for only a fraction of total cost of a disaster, particularly in the case of large-scale events (Tierney 1997; Pielke and Pielke 1997; Lindell and Prater 2003; Hallegatte et al. 2007). After an event, the total economic costs can be amplified through: (1) spatial or sectoral diffusion of direct costs into the wider economic system over the short-term (e.g. through disruptions of lifeline services, such as communication and transportation networks) and over the longer term (e.g. sectoral inflation due to demand surge, energy costs, company bankruptcy, job losses, larger public deficit, or housing prices); (2) social responses to the shock (e.g. loss of confidence, change in expectations, indirect consequences of inequality deepening); (3) financial constraints impairing reconstruction (e.g. low-income families cannot finance rapidly the reconstruction of their home); and (4) technical constraints slowing down reconstruction (e.g. availability of skilled workers, difficulties in equipment and material transportation, difficulties in accommodating workers). These additional losses are described as indirect economic costs. These costs are dependent on the scale and timing of the event and on local conditions; as such, they are difficult to project. However, estimates of indirect costs must be included in decision-making 
to ensure a fair cost-benefit analysis of protection infrastructures or mitigation actions. Understanding the key mechanisms that regulate indirect effects may also provide useful knowledge on how to respond to a disaster.

Indirect costs can be defined as the reduction in production of goods and services, measured in terms of value-added (to avoid double-counting issues). These costs are important, as they participate in the reduction of available consumption, and therefore in the impact on welfare. For example, if a $\$ 100 \mathrm{~m}$ plant is destroyed and immediately rebuilt, the total loss would be $\$ 100 \mathrm{~m}$; whereas, if reconstruction is delayed by 1 year, the total consumption loss will be the sum of the replacement cost (the direct cost) and the value-added of 1 year of production (the indirect cost). Here, our estimates of indirect costs include business interruption in the event aftermath, value added losses during the reconstruction period and loss in housing services. The value of such production losses, in a broad sense, can be very high in some sectors, especially when basic needs are at stake (housing, health, employment, etc.). Of course, the real cost of a disaster is not only economic, and also includes fatalities, injuries, moral damages, historical and cultural losses, environmental losses, societal disruptions. In this study, however, we consider only the economic costs.

\subsection{Indirect loss estimation}

This study uses the Adaptive Regional Input-Output (ARIO, see Hallegatte 2008) model to assess indirect economic losses in the Mumbai Metropolitan Region. ${ }^{3}$ This dynamic model represents the 'amplifying' processes described above, taking into account changes in production capacity due to productive capital losses and adaptive behaviour in disaster aftermaths. Details of the model and methodology are given in Appendix B. It should be noted that the uncertainties in this type of modelling are large, and therefore, results should be interpreted as indicative of the scale of potential damages.

Indirect losses are calculated by sector based on the upper bound of the direct loss estimates given above. To achieve this, direct losses estimates are distributed by sector. Residential losses are assumed to only affect households, while industrial and commercial (and infrastructure) losses are divided between the ARIO sectors dependent on their activity and size (Table 7). The distribution of infrastructure losses is made according to empirical observations on previous events. Table 7 shows the distribution of direct losses between sectors for the July 2005 event; sectors 15 ("electricity, gas and water supply") and 16 ("transportation") have the largest direct losses because if we take into account public infrastructures, these sectors have the highest quantity of productive capital.

\subsection{Case study of July 2005}

Using the ARIO model, the local Input-Output (IO) table and the loss distribution per sector (Table 7), one can simulate the consequences of the flooding on the

\footnotetext{
${ }^{3}$ The economic model, therefore, considers a region that is larger than just the city of Mumbai. We assume, however, that the Mumbai Metropolitan Region is only affected by the flood losses in the Greater Mumbai, where direct losses are estimated. Input-Output data for the region are from Pohit (2000).
} 
Table 7 The ARIO sectors and their equivalent RMS exposure type

\begin{tabular}{|c|c|c|c|}
\hline \multicolumn{2}{|c|}{ ARIO sector } & \multirow{2}{*}{$\begin{array}{l}\text { RMS exposure } \\
\text { type } \\
\text { Industrial }\end{array}$} & \multirow{2}{*}{ 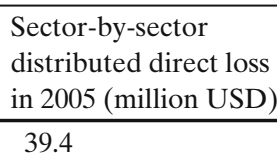 } \\
\hline 1 & Primary & & \\
\hline 2 & Food products & Industrial & 3.9 \\
\hline 3 & Beverages related & Industrial & 0.9 \\
\hline 4 & Cotton textiles & Industrial & 25.3 \\
\hline 5 & Wool, silk, jute etc. . & Industrial & 22.6 \\
\hline 6 & Textile products & Industrial & 16.5 \\
\hline 7 & Wood and wood products & Industrial & 1.1 \\
\hline 8 & Paper and paper products and printing & Industrial & 14.2 \\
\hline 9 & Chemicals and chemical products & Industrial & 43.7 \\
\hline 10 & Petro-products & Industrial & 98.2 \\
\hline 11 & Basic metals and alloys & Industrial & 26.1 \\
\hline 12 & Machinery and equipment & Industrial & 117.5 \\
\hline 13 & Transport and equipment & Industrial & 26.7 \\
\hline 14 & Construction & Industrial & 39.8 \\
\hline 15 & Electricity, gas, water supply & Industrial and infrastructure & 227.5 \\
\hline 16 & Transportation & Industrial and infrastructure & 279.4 \\
\hline 17 & Rest of manufacturing & Industrial & 59.1 \\
\hline 18 & Storage and warehousing & Industrial & 91.9 \\
\hline 19 & Communication & Commercial & 10.6 \\
\hline 20 & Trade & Commercial & 140.8 \\
\hline 21 & Hotels & Commercial & 11.1 \\
\hline 22 & Banking & Commercial & 53.6 \\
\hline 23 & Insurance & Commercial & 13.4 \\
\hline 24 & Education, research, health & Commercial and infrastructure & 122.0 \\
\hline 25 & Public administration & Commercial and infrastructure & 127.3 \\
\hline 26 & Household & Residential & 300.0 \\
\hline
\end{tabular}

The final column illustrates the distribution of the estimates direct losses by sector for the July 2005 event

Mumbai economy. This simulation is reproduced in Fig. 4, which displays the change in value added (VA) in the 25 sectors ( $x$-axis) as a function of time in months ( $y$-axis). The simulation shows both the reduction in VA in the months following the event, and the VA increase in construction sector (sector \#14) due to reconstruction needs. The losses and gains partly compensate, but the aggregated VA loss (without housing sector) for the Mumbai Metropolitan Region is still \$395 million, for \$1.5 billion of direct losses. This reduction corresponds to $1.4 \%$ of annual regional GDP; a very significant economic impact. Given that we have no empirical information on the economic impact of the July 2005 floods, we are not able to validate these results in a detailed manner. A further study on job losses would be a good indicator of welfare losses; unfortunately, consistent data including formal and informal employment in Mumbai could not be found.

The model also provides an assessment of the "production loss" in the housing sector. Indeed, houses and residential buildings produce a housing service that plays a major role in ensuring local well-being. The decrease in housing services because of damaged houses and buildings has, therefore, to be taken into account. The model, because it reproduces the reconstruction period and duration, can assess the total 


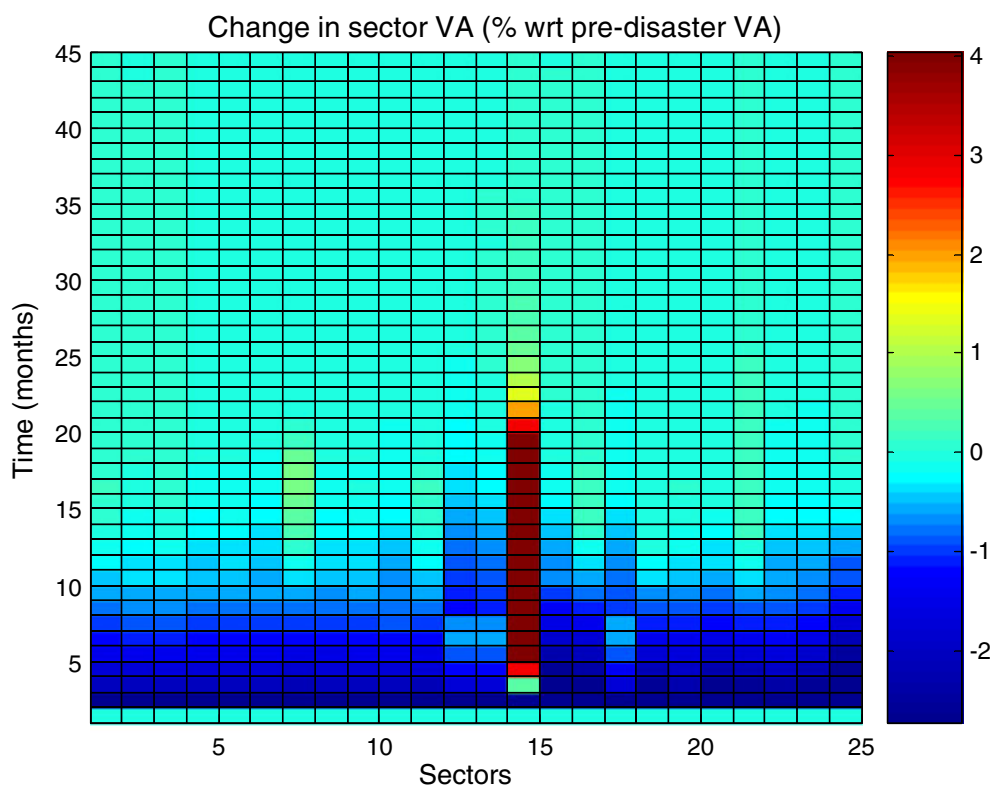

Fig. 4 Sector-by-sector change in value added (in \%). Note the large increase in production in the construction sector (\#14), and the increase in the wood and wood-product sector (\#7), due to intermediate consumptions of the construction sector

loss in housing service production. In the July 2005 case, the model estimates this loss at \$30 million. The overall indirect loss, i.e. the sum of the "production loss" in the housing sector and the aggregated VA loss, is estimated to be $\$ 425$ millions.

It should be noted that the long term effects (here, more than 20 months after the shock) are due to a budgetary constraint: households that have gone into debt (or have reduced their savings) in order to pay for reconstruction, consume less while they pay off their debt or rebuild their savings, thus reducing the local final demand. In the case of Mumbai, this effect is important because the flood insurance penetration rate is very low. For example, in developed countries, the large insurance penetration and government aid for the non-insured (typically) prevent or mitigate this kind of long-term demand effects.

\subsection{Link between direct losses and total losses}

Indirect economic losses, i.e. the decrease in the values added in all sectors during the reconstruction phase, are found to be significant in this analysis, and are strongly non linear with respect to direct losses. This nonlinearity arises from the coupled contributions of different factors. First, a larger disaster causes larger production losses at a given point in time. Second, a larger disaster leads to a longer reconstruction period and, therefore, production losses last for a longer period. Third, in the case of a big disaster and a non-homogenous repartition of damages, production bottlenecks appear in the production system; one or several sectors are not able to produce enough to satisfy the intermediate demands of other sectors. As a consequence, these sectors have in turn to reduce their production. These forward propagations 
Fig. 5 Change in total value-added (excluding housing services) as a function of time, for the 100 years return period flood event in present conditions and July 2005 flooding

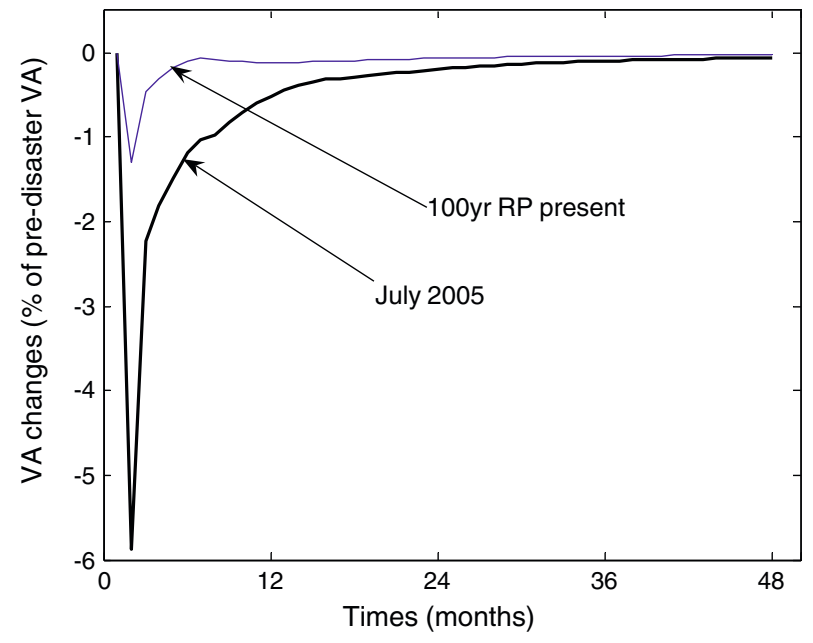

amplify the initial shock. The two first factors are illustrated in Fig. 5, which shows the reconstruction dynamics in a 100-year return period event in present conditions (i.e. $\$ 600$ millions direct losses) and in a simulated July 2005 event (i.e. $\$ 1.9$ billions), corresponding to a return period of between 130-years and more than 200-years in present conditions. In the second case, the instantaneous reduction in value added exceed $6 \%$ of the pre-event level the month of the event, while it is only about $1 \%$ in the first case. Moreover, total production is back to its initial level about 1 year after the shock in the first case, while it takes more than 2 years in the second case.

As a result, indirect losses amount only to around $\$ 100$ millions for the 100 -year return period event compared to $\$ 425$ millions for the July 2005 event; that is, for direct losses multiplied by 2.5, the indirect losses are multiplied by 4 . Figure 6 illustrates the non-linearity between direct and indirect losses: we created hypothetical disasters, with the same reparation of losses as for July 2005 flooding, but multiplying the

Fig. 6 Relationship between direct losses due to an event and VA losses (productive sectors plus housing sector)

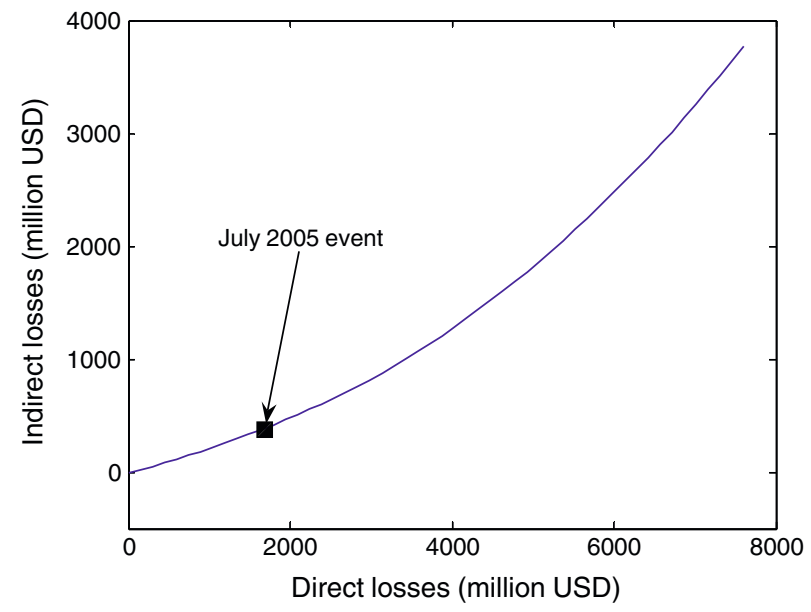


Table 8 Upper estimation of total losses (direct+indirect, including loss in housing services) due to various types of events in present-day and future conditions

\begin{tabular}{|c|c|c|c|c|c|c|}
\hline \multirow[t]{3}{*}{ Type of event } & \multicolumn{6}{|c|}{ Projected flood losses ( $\$$ million USD) } \\
\hline & \multicolumn{3}{|c|}{ Present-day } & \multicolumn{3}{|l|}{$2080 \mathrm{~s}$} \\
\hline & $\begin{array}{l}\text { Direct } \\
\text { losses }\end{array}$ & $\begin{array}{l}\text { Indirect } \\
\text { losses }\end{array}$ & $\begin{array}{l}\text { Total } \\
\text { losses }\end{array}$ & $\begin{array}{l}\text { Direct } \\
\text { losses }\end{array}$ & $\begin{array}{l}\text { Indirect } \\
\text { losses }\end{array}$ & $\begin{array}{l}\text { Total } \\
\text { losses }\end{array}$ \\
\hline Simulated July 2005 & 1,910 & $425(18 \%)$ & 2,335 & & & \\
\hline 50-year RP & 570 & $95(14 \%)$ & 665 & 760 & $130(15 \%)$ & 890 \\
\hline 100-year RP & 600 & $100(14 \%)$ & 700 & 1,890 & $415(18 \%)$ & 2,305 \\
\hline 200-year RP & 600 & $100(14 \%)$ & 700 & 1,990 & $445(18 \%)$ & 2,435 \\
\hline
\end{tabular}

In parenthesis is the contribution of indirect economic losses to the total losses

total amount of direct losses by a factor ranging from 0 to 6 , therefore investigating hypothetic events causing up to $\$ 8$ billion in losses. The ARIO model provided the amount of indirect losses for each of these disasters; at roughly $\$ 8$ billions of direct losses, the indirect losses become equal to half the direct losses.

\subsection{Future evolutions of flood risks in Mumbai}

With a higher probability of larger direct costs from flooding in the 2080s (Section 3), we would expect: (1) more significant indirect costs in the future; and (2) for indirect costs to account for a larger proportion of the total losses. This finding is shown in Table 8 below. For example, the total losses for a 100 -year return period event are projected to be more than a factor 3 greater by the 2080s. The contribution of indirect losses to total losses increases from $14 \%$ (\$100 millions) in present-day situation to $18 \%$ ( $\$ 415$ millions) in the 2080s.

Figure 7 shows the reconstruction dynamics for various types of events in present and future (2080s) conditions, compared to the simulated July 2005 event. It shows that there are qualitative differences between 50-, 100- and 200-year RP events

Fig. 7 Variations of total VA as a function of time for the 50 , 100 and 200 years return period in present conditions and in future (2080s) conditions, compared to July 2005 flood event

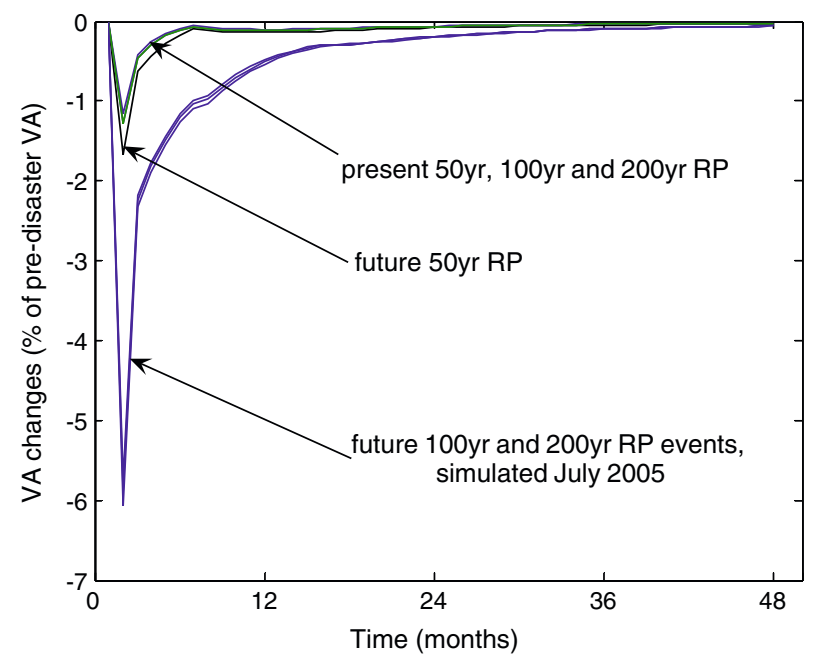


today and the future events. The future 100 and 200 year event, indeed, are close to the July-2005 event, which is really exceptional in the current climate. In Mumbai, therefore, and according to this modelling exercise, the July 2005 event represents a useful proxy for what can be expected to occur on average once a century in the future.

\section{Adaptation to flood risk in Mumbai}

Following the 2005 flooding, the Government of Mumbai established a fact-finding committee (FFC) (the CHITALE Committee) to investigate the causes of the disaster and make recommendations to reduce future risks. Several recommendations were made, with much emphasis on measures to improve the city's drainage systems, and were accepted by the Maharashtra state cabinet in May 2006. Simultaneously, the government launched the Mithi River Bed Restoration Plan, expected to be completed in June 2010. The plan incorporates several risk reducing measures, including: (1) restoring and widening river and drainage channels; (2) improvements to infrastructure and housing (including retrofitting and renovation of cessed buildings and improvements to the condition of informal settlements); (3) land use policies and planning; (4) extended risk transfer initiatives; and (5) improved preparedness, including monitoring, early warning, emergency planning, risk modelling and risk education (MEERP 2007).

While these actions are commendable, they do not appear to consider the potential impacts of climate change on the long-term planning horizon. Not considering climate change in present-day disaster risk management can increase potential future vulnerability and limit flexibility to adapt, leading to costly maladaptation (Fankhauser et al. 1999). In addition, to the changes in rainfall explored in this study, Mumbai will also be exposed to sea level rise and potential increases in the risks associated with of heat waves, tropical cyclones and storm surges. Managing these combined risks could require significant revision of urban planning practices across city to integrate disaster risk reduction and climate change adaptation measures (as well as greenhouse gas mitigation) into day-to-day urban development and service delivery activities (Revi 2005).

To demonstrate the importance of an integrated approach to disaster risk reduction and climate change adaptation, below we provide a simple analysis of the potential risk reducing benefits of four potential policy options, two relevant to reducing direct losses from flooding and two relevant to reducing indirect losses. These are not intended to guide specific policy (they are too simplified to do so) and do not represent a complete list of options, but do serve to demonstrate the potential of adaptation to limit climate change damages and the need to incorporate it into decision-making around disaster risk management today.

Reducing direct losses from flooding Figure 8 shows the estimated total losses (direct and indirect) associated with a 1-in-100 year flood event in Mumbai under five scenarios (respectively, from left to right in Fig. 8): (1) present-day; (2) the 2080s (note, under the one 'high-end' climate scenario considered in this study and with an unchanged city); (3) the 2080s, with a reduction in the vulnerability of properties (e.g. representing strengthened building codes); (4) the 2080s, with an improvement 
Fig. 8 The estimated total (direct + indirect) losses for a 1-in-100 years flood event in Mumbai under five scenarios (from left to right): (1) present-day; (2) 2080s-using the one 'high-end' scenario considered in this study and an unchanged city; (3) 2080s, assuming properties are made more resilient and resistant to flooding (e.g. through building codes); (4) 2080s, assuming the drainage system is improved such that it can cope with a 1-in-50 years rainfall event; and (5) combined property and drainage improvements

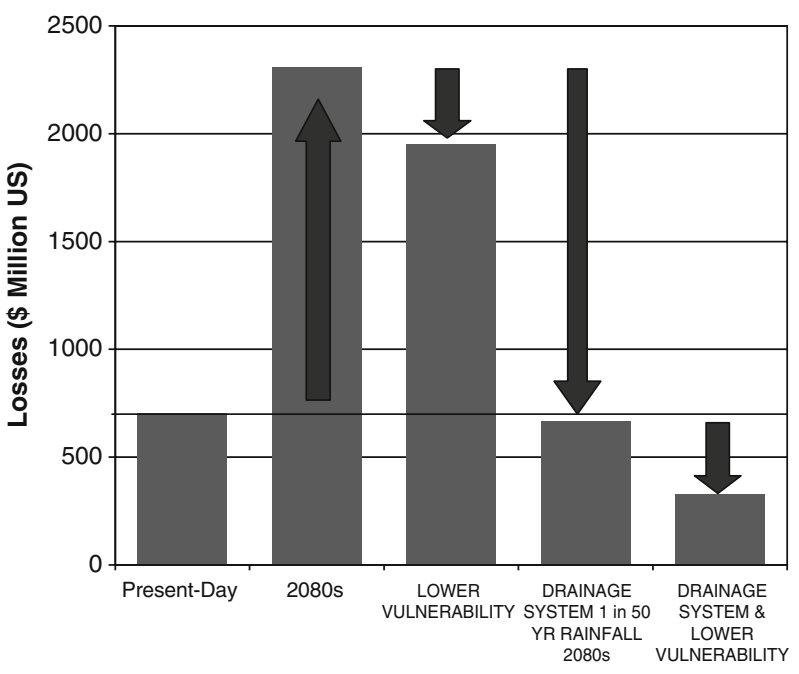

in the drainage system; and (5) the 2080s, with a combination of reduced vulnerability of properties and improved drainage. The 'lower vulnerability' scenario assumes a $15 \%$ reduction in vulnerability for a 1 -in-100 year event (achieved through, for example, building improvements incentivised by building codes) and the improved drainage scenario assumes that the drainage system has been upgraded such that it can cope effectively with a (2080s) 1-in-50 year rainfall event. ${ }^{4}$ The uncertainties in individual estimates are great and the effectiveness of measures will depend strongly on the quality of implementation, however, the figure demonstrates that with certain options or combinations of options, Mumbai may be able to offset the increase in risk due to climate change (even under this high-end scenario) and also that such measures can also have significant benefits today; for example, upgrading the drainage system such that it could cope with a 1-in-50 year event today, could reduce losses from a 1-in-100 year event by around $70 \% .^{5}$

Reducing indirect losses from flooding The ARIO model allows us to assess the benefits of sets of policies that aim to enhance disaster recovery; reducing the lost production due to property damages and therefore the indirect costs of flooding. Two instruments are explored here: firstly, increasing flexibility in the capacity of the construction sector, to speed reconstruction; and secondly, the provision of insurance.

\footnotetext{
${ }^{4}$ A 50-year standard is higher than what is usually used for drainage system (i.e. 10 or 20 years), but the Mumbai climate and the vulnerability of the city to heavy precipitations may justify such a strict standard.

${ }^{5}$ The impact of an improved drainage system is assessed very simply in this study and so should be treated as illustrative only. To make this estimate, we define a relationship between affected exposure $(\mathrm{E})$ and rainfall $(\mathrm{P})$ at each return period (i.e. $\mathrm{E}_{R P}=\mathrm{f}\left(\mathrm{P}_{R P}\right)$ ) from the original 'un-adapted' scenario. For the adapted scenario, we estimate a new function $\mathrm{f}^{\prime}$ (by shifting $\mathrm{f}$ ) such that $\mathrm{E}_{50}=0$. We then assume: (i) no flooding for rainfall events with a return period of up to 50 years; and (ii) rainfall with a return period of above 50 years leads to an affected exposure $\left(\mathrm{E}^{\prime}\right)$ given by $\mathrm{E}^{\prime}{ }_{R P}=\mathrm{f}^{\prime}\left(\mathrm{P}_{R P}\right)$.
} 
Adaptive capacity of the construction sector Increasing the flexibility of capacity of the construction sector means that damaged buildings and infrastructure can be repaired or replaced more quickly following a disaster, reducing lost production. This can represent, for example, the ability of workers to increase their productivity, or the possibility of workers and equipments from outside the affected region to move there to speed up reconstruction. ARIO allows us to explore the benefits of such flexibility in terms of avoided indirect costs through running scenarios of its sectoral overproduction parameters. We find that, for the July 2005 event, the indirect effect of the disaster on the local economy can vary by a factor of 4 (Fig. 9), depending on the amplitude and quickness of response of the construction sector.

From a policy perspective, this high sensitivity is good news, as it suggests that large economic losses can be avoided with increased flexibility in the construction sector production capacity. The flexibility depends heavily on the pre-event conditions; for example, if idle capacities are present (e.g. unused equipment) they can be mobilized to cope with the disaster (West and Lenze 1994; Hallegatte and Ghil 2008b), whereas if capacities are fully used then no additional capacity can be mobilized. The flexibility of the construction section could be enhanced through:

- Enabling qualified workers to settle down temporarily in the affected region (e.g. by providing working permit or helping workers to find accommodation).

- Organising and sharing reconstruction resources among regions, states or cities and setting super-national policies to ensure reconstruction capacity is adequate to cope with possible disasters.

- Empowering governments to mobilizing their workers (e.g., soldiers) and their equipments to speed up reconstruction.

Past disasters illustrate the barriers to efficient reconstruction and suggest good practices. For instance, in the Katrina aftermath, many qualified workers from the entire U.S. moved to New Orleans to help reconstruct the city and capture higher construction-sector wages. Most of these workers, however, had to leave the area rapidly because they could not find proper accommodation or because of insufficient

Fig. 9 Indirect losses to direct losses ratio, as a function of the amount of direct losses, for four sets of adaptation parameters

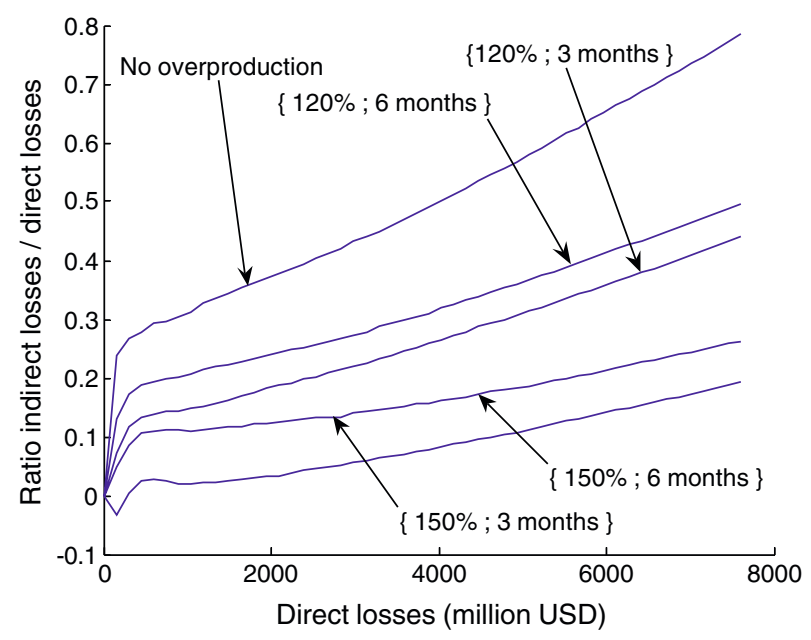


public services. Providing housing to temporary workers, therefore, seems to be extremely important to speed up reconstruction. Also, these workers left the region because the reconstruction of many buildings was delayed by legal problems, either due to delays in insurance claim payments or to the slow approval of building permits. For reconstruction to be as effective as possible, therefore, it seems that all administrative and legal issues must be solved rapidly, to benefit for the mobilization of internal and external resources.

The benefits of insurance Financial constraints can play a significant role in delaying reconstruction (Benson and Clay 2004), and can even lead to a suboptimal reconstruction with consequences on productivity (Hallegatte and Dumas 2008a). Insurance allows individuals to share risks; in exchange for a regular premium payment individuals receive a payout if they experience damage. This means that individuals do not absorb all their reconstruction costs and have fast access to capital in the aftermath of a disaster.

We can use the ARIO model to investigate the benefits of insurance by exploring the sensitivity of indirect losses to the insurance penetration rate $(\gamma)$ assumed in the model. In ARIO, the insurance penetration affects the response to the shock through two mechanisms: first, if the insurance penetration of households is low, they have to pay for their reconstruction (either directly, or by getting into debt and then paying off later), and reduce their consumption in order to so. Second, if the insurance penetration of firms is low, firms have to pay for reconstruction, reducing their profits. As a portion of these profits normally goes to local households, this affects the household budget, also reducing their consumption.

Figure 10 illustrates the effect of insurance penetration on the household's budget, for a July 2005 like flood estimated using the ARIO model. Three scenarios are included: (1) $\gamma=0$, equivalent to the absence of insurance system, but with an access to credit; (2) the current value of flood insurance penetration estimated by RMS ( $\gamma=0.08$ for households, $\gamma=0.15$ for firms); and (3) $\gamma=1$, representing the situation where all the reconstruction is paid for by insurance. It is important to note

Fig. 10 Household budget as a function of time, for three different penetration rates: $\gamma=0$ (no insurance), current value estimated by $\operatorname{RMS}(\gamma=$ 0.08 for households and $\gamma=$ 0.15 for businesses) and $\gamma=1$ (reconstruction is entirely paid by the insurance system)

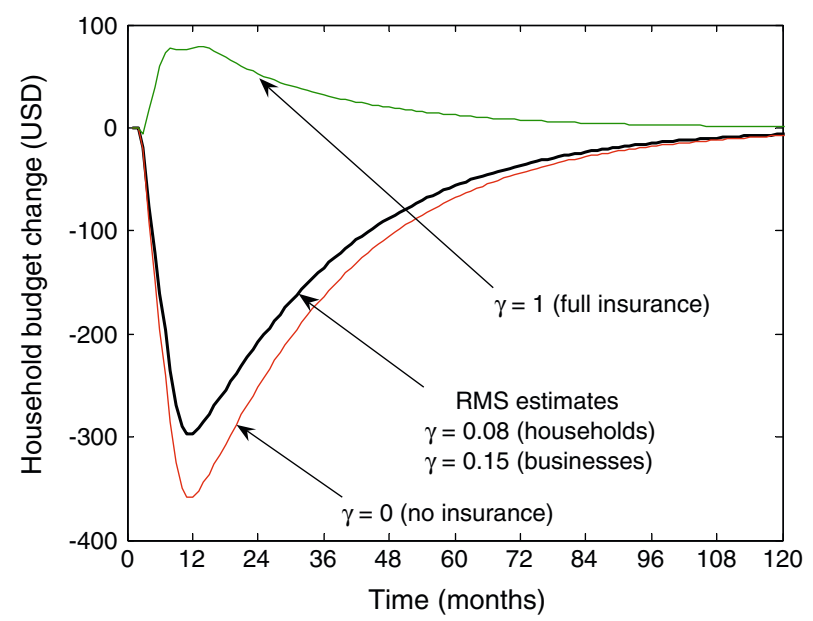


that our "insurance penetration rate" does not represent the fraction of the total amount of houses that is insured, but the fraction of the total value of goods that is insured (never equal to one in the real world, because of ceilings or deductibles). Moreover, this analysis investigates only disaster situations, in which insurance provides instantaneous net benefits, not non-disaster situations, in which insurance is a net cost. So, we investigate insurance benefits, which should be compared with its costs in a full analysis of adaptation options.

Where the budget is positive in Fig. 10, it can be interpreted as the total amount of savings of households, and where negative it represents debt. We assume that the budget is equal to zero before the disaster and that it tends to return to the initial situation. Figure 10 shows that the lower the penetration rate the more households have to get into debt in order to pay for their reconstruction. When the penetration is very large, households make savings after the disaster. This occurs because in this case, the decrease in production is more important than the decrease in demand (through the decrease of incomes). Households are rationed and consume less than what they would like to and as a result, they involuntarily save money.

Variations in household budget affect the local demand, as households in debt reduce their consumption. This decrease in demand affects local production in the long term, as shown in Table 9. When the reconstruction is paid for by the insurance system, indirect losses are reduced by $37 \%$, compared to the best guess situation, and by $42 \%$ compared to the no-insurance situation. This demonstrates that even though the gap between two insurance systems does not exceed $0.1 \%$ of the baseline valueadded at a given point in time, the overall effect on total indirect losses can be very important.

The difference in indirect losses between the no-insurance and the full-insurance cases arise from two factors. First, in presence of insurance or perfect access to credit, businesses and households can restore their productive environment and equipment, allowing for a more rapid recovery of the economic activity. Second, insurance prevents a reduction in the final demand from affected businesses and households that have to rebuild their savings or pay back their debt. In this analysis, it is the second mechanism that explains the difference, since households are assumed to have full access to credit in absence of insurance. With a limited access to credit, a case that will be investigated at a later stage, indirect losses would be even larger than in the worst case presented here.

These results provide insight on the aggregated losses that can be avoided at the macroeconomic level due to a well developed insurance system. In addition, a generalized insurance scheme (that can be accessed by all households and businesses) would help the poorest households and the most fragile businesses to cope with floods. This means that insurance would yield macroeconomic benefits (estimated here), and microeconomic benefits at the household level (not explicitly estimated here, but suggested by Fig. 10). Microeconomic benefits include in particular the avoidance of increased poverty and inequality. Even though they are difficult to

Table 9 Total indirect losses, as a function of the insurance penetration rate, for a July-2005-like flood

\begin{tabular}{ll}
\hline Insurance penetration rate & Total indirect losses (\$ million USD) \\
\hline 0 & 455 \\
RMS estimates & 425 \\
1 & 265 \\
\hline
\end{tabular}


estimate in monetary terms, these benefits should be taken into account, e.g. in the cost-benefit analysis of the implementation of a micro-insurance scheme.

Flood insurance coverage would, therefore, be an interesting strategy to reduce flood vulnerability and improve aggregate economic resilience in Mumbai, and to prevent poor households from falling into poverty after a flood. Insurance, however, has a cost between disasters and create affordability issues, which are not investigated here. Also, insurance has to be combined with risk-reducing landuse planning and other regulations to avoid incentivising over-development and growth in exposed areas. In the UK and for many commercial properties in the developed world, flood insurance is obtainable from the private insurance market. For residential coverage, many countries have established national flood insurance systems (e.g., the French Cat-Nat system, the Florida Hurricane Catastrophe Fund). These systems may provide useful models for Mumbai; a full discussion of their relative advantages and disadvantages is beyond the scope of this paper. It is worth mentioning the benefits of insurance relative to other 'financial safety pools'. Local and familial solidarity is an established mechanism in many developing countries, but the disadvantage is that access to funding can be slower and limited, and may be impossible when an area or family are all affected at the same time (as is often the case for large-scale disasters like floods). Government support is often necessary to some extent (for instance, after Katrina, the U.S. Federal government more or less replaced insurance for households that had no flood insurance; Lubell 2006). But relying on it creates inefficient uncertainty for economic actors (e.g., because, after an event, they cannot know the exact scope of the government support they will receive) and can lead to moral hazard (e.g. if households know that they will be compensated by government, they will have little incentive to reduce their own risks or to pay for insurance). International support (grants or goods provided to affected people) can help reconstruction, but (in addition to the moral hazard issue) is very volatile and unpredictable. Finally, an improved access to credit (especially for the underprivileged) can help during the post-disaster period; e.g. the government guaranteeing reconstruction credits. As a conclusion, if the frequency and intensity of extreme events in Mumbai is to increase, the development of the insurance system and other financial services could have significant benefits in combination with other existing risk sharing mechanisms.

\section{Discussion: adaptation planning and uncertainty}

This study has demonstrated a number of approaches to enable an adaptation planner to quantify risks associated with climate change and the benefits of adaptation. An important limitation of this study is that it does not attempt to fully quantify the uncertainties in the analysis. Uncertainty is incorporated at each stage of an analysis (Table 10). Fully quantifying uncertainties at each stage is likely to lead to the characteristic 'explosion' of uncertainty (Carter et al. 2007). A number of previous studies have suggested that a 'policy-first' approach, where the quantitative analysis is designed from a policy perspective (rather than a scientific perspective) to evaluate the desirability of specific adaptation options against a set of defined objectives, would help to narrow uncertainties in the analysis (Dessai et al. 2009). Recognising the scale of the uncertainties, such a process can utilise methods such as 
Table 10 Summary of uncertainties incorporated into final estimates

\begin{tabular}{|c|c|}
\hline Source of uncertainty & Description \\
\hline Present-day hazard & $\begin{array}{l}\text { Includes uncertainties introduced by statistical analysis of rainfall events } \\
\text { from short data records; the urban flood model; and extrapolations from } \\
\text { one catchment (Mithi) to city-scale. Figure } 2 \text { suggests that uncertainties } \\
\text { related to statistical analyses could be large (e.g. estimates of rainfall } \\
\text { at given return periods were doubled when the } 2005 \text { event was included } \\
\text { in the analysis) }\end{array}$ \\
\hline Future hazard & $\begin{array}{l}\text { Includes uncertainties in emissions scenarios; climate modelling, flood } \\
\text { modelling, and those introduced by statistical downscaling }\end{array}$ \\
\hline Exposure & $\begin{array}{l}\text { Our approach to estimating property values is sensitive to uncertain } \\
\text { estimates of insurance penetration. Estimates of future exposure trends } \\
\text { can be expected to significantly impact estimates of risk and the } \\
\text { benefits of adaptation }\end{array}$ \\
\hline Vulnerability & $\begin{array}{l}\text { Uncertainties in estimates of } 2005 \text { vulnerability were quantified by the } \\
\text { analysis (Section 3.3) and could be further refined through study of } \\
\text { other flood events. Extrapolation of } 2005 \text { vulnerability estimates to } \\
\text { future events incorporates uncertainty }\end{array}$ \\
\hline Indirect loss modelling & $\begin{array}{l}\text { Local economic data are largely unavailable, and there is a large } \\
\text { uncertainty in the current local economic structure. Economic modelling } \\
\text { of disaster consequences is difficult and various modelling strategies } \\
\text { coexist (e.g., CGEs, Input-Output, econometric models), leading to } \\
\text { large differences in results }\end{array}$ \\
\hline
\end{tabular}

robust decision-making to design strategies that are flexible under a range of climate scenarios (Lempert and Collins 2007; Hallegatte 2009; Ranger et al. 2010). These types of approaches still require quantification of potential risks and benefits of adaptation. For example, the risk-based tools presented here are able to demonstrate that there are strong benefits from a number of adaptation measures with or without climate change. The tools can also be used to identifying if and where current disaster risk management plans may become future maladaptations and how these plans could be adjusted to make them robust to long-term climatic changes.

Each of the uncertainties outlined in Table 10 could significantly affect estimates of risk. Some are likely to be irreducible on the timescales that many adaptation decisions must be made; for example, uncertainties related to emissions scenarios and climate models. However, many of the other uncertainties are reducible and further study in these areas could help to refine risk estimates in the near-term. Of particular importance is monitoring and research into understanding current levels of hazard, exposure and vulnerability; these elements form the starting point of an analysis of risk and therefore, reducing these uncertainties is likely to be of high value in adaptation decision-making as well as present-day disaster risk management.

\section{Conclusions}

This study has demonstrated the application of a series of tools aimed at quantifying risk and the benefits of adaptation to inform adaptation strategies, using the case of flood risk in Mumbai. While the study does not aim to provide a complete assessment, it does demonstrate the significant current vulnerability of Mumbai to 
heavy precipitation, as well as the high potential sensitivity to climate change and the strong need for effective and integrated climate change adaptation.

The findings of the study show that disaster risk management and adaptation can have significant benefits both today and in the future, for example, our estimates suggest that by upgrading the drainage system in Mumbai, losses associated with a 1-in-100 year flood event today could be reduced by as much as $70 \%$, and through extending insurance to $100 \%$ penetration, the indirect effects of flooding could be almost halved, speeding recovery significantly. Given the uncertainties in future rainfall projections, it may be prudent to explore win-win measures that provide benefits under the broad range of climate scenarios-we demonstrate that upgrading the drainage system and supporting an effective insurance mechanism may be examples of such no-regrets measures, others include spatial planning to manage new construction out of high risk areas and increasing public risk awareness.

The Government of Maharashtra has laid out comprehensive plans to reduce and better manage risks associated with flooding in Mumbai. However, it is not clear whether these plans adequately account for the potential increases in flood hazard with climate change. Several studies have shown that not considering climate change in long-term planning and investment decisions today can lead to potentially costly maladaptation. In planning disaster risk reduction, it is also important to consider other hazards to which the city is exposed and the effects of climate change on each (in particular, sea level rise, heavy precipitation, storm surge, high tides and tropical cyclone risks). Policies to limit long-term flood hazard will need to be considered alongside policies related to other risks and objectives (e.g. improving overall housing quality or reducing greenhouse gas emissions) to identify synergies and minimise conflicts. For example, measures to mitigate sea level rise and inland flooding must be considered in tandem as sea level rise could impair any drainage improvements in the city.

Further research is also required to consider the implications of uncertainties in climate projections for adaptation planning in Mumbai, for example, this study should be extended through the use of multiple projections from a range of available Global Climate Models and Regional Climate Models. A single scenario of future climate, as used here, is not by itself adequate to inform robust adaptation decisions. Uncertainties in climate model projections are not likely to be significantly reduced on the timescale of many adaptation decisions and therefore, further research is required to demonstrate the integration of quantitative risk analysis tools, like those presented here, with approaches to decision-making under uncertainty. We also discuss the benefits of focussing research and monitoring towards reducing the more 'reducible' uncertainties associated with managing extreme events, in particular related to understanding levels of current hazard, exposure and vulnerability; such investments would have significant benefits for both climate change adaptation and present-day disaster risk management.

\section{Appendices}

\section{A SWMM: urban flood modelling in Mumbai}

The Storm Water Management Model (SWMM) was been developed by the US Environmental Protection Agency for use in the urban hydrology and is widely 
Table 11 The input assumptions of the SWMM model for the Mithi River Basin

Summary of input assumptions and data sources

Rainfall data as collected and simulated from the Santa Cruz IMD rainfall station

The total catchment is divided into 9 sub-catchments with channel characteristics taken from

Google Earth

The Slope values in \% are derived from SRTM Digital Elevation Model (DEM)

The soil is assumed to have a slow infiltration rate (Hydrologic Soil Group C). The impervious area depression storage is assumed to be $5 \mathrm{~mm}$

Assume manning's coefficient of 0.014 for irregular channels and impervious area; and 0.035 for pervious areas (based on Sharma and Gupta 2006)

Infiltration parameters from Soil Conservation Service Curve Number, based on the land use type The Kinematic Wave method of flow routing is used

Tidal effects are neglected

applied in flood simulation studies. The basic model components include the physical characteristics of the basin such as topography, soil types, land use characteristics, and climate characteristics such as evaporation, temperature and precipitation. SWMM has the capacity to model every aspect of urban drainage; combining sewers and the natural drainage, whereas other river flood models are generally restricted to natural drainage. This makes it most appropriate for modelling flood risk in the Mumbai area.

One of the most important inputs to the model is topographic data in the form of a digital elevation model (DEM). This data is obtained from the Shuttle Radar Topography Mission (SRTM). The SRTM instrument obtained elevation data on a near-global scale to generate the most complete high-resolution digital topographic database of Earth. The $90 \mathrm{~m}$ DEM derived from SRTM has been used as primary source for elevation data and is smoothened using standard interpolation techniques. The DEM is further enhanced through validation against topographic maps from the Survey of India.

Table 11 gives an overview of the input assumptions and data sources used in the SWMM model for the Mithi River Basin. It should be noted that tidal effects are neglected in this analysis, giving a potential negative bias on flood extent estimates. Further information on SWMM can be located at: http://www.epa.gov/ednnrmrl/ models/swmm/index.htm

\section{B The ARIO model}

The ARIO model (Hallegatte 2008) is based on IO tables and a hybrid modelling methodology, in the spirit of Brookshire et al. (1997). The model takes into account (1) the propagation among sectors of reduced productions due to disaster damages; (2) the propagation among sectors of reduced demands due to disaster damages; (3) the large demand in the construction sector due to reconstruction needs; (4) the economic-agent behaviours to cope with disaster consequences (e.g., by increasing their production when demand is large, or by finding alternative suppliers when the original ones cannot produce); (5) the limitations in resource movement between sectors (e.g., the construction sector cannot grow instantaneously by hiring workers from other sectors; it is limited by the availability of qualified workers); (6) the 
interaction with outside the affected regions (through imports and exports). Importantly, the model assumes that the economy will eventually return to its initial situation. Also, impacts outside the Mumbai region are not assessed, because these impacts are distributed over a large number of economic actors, and are therefore small (often negligible) on a per capita basis.

The model is applied to Mumbai using sector-by-sector macroeconomic data from the National Council of Applied Economic Research downscaled to the Mumbai region. For this study, we introduced three main modifications in the ARIO model initial setting, which is used in the Copenhagen case study in this project (Hallegatte et al. 2011b):

- The modelling of reconstruction demand has been modified to take into account the urgency in reconstruction. In the new version, it is assumed that, in absence of any constraint in construction-sector production capacity, all damages would be repaired 3 months $(\tau)$ after the disaster. Of course, because of technical, financial, and practical constraints, the actual reconstruction time can be much longer.

- The rationing scheme is modified. In the current version, there is a three-stage rationing: (1) intermediate consumptions are served first, to ensure that total output is maximum; among industries, the rationing is proportional, with each sector receiving the same fraction of its demand; (2) reconstruction needs and local demand is served second, with again a proportional rationing between the two; (3) exports are served last, if all other demands can be fully satisfied. Compared with the previous version, this rationing scheme gives a higher priority to local demands and lead to more optimistic results.

- When applying ARIO to Mumbai, the assumption that all losses are paid by insurance claim is not acceptable any more. According to RMS, flood insurance penetration in Mumbai is around 8\% for households and 15\% for businesses. The fact that businesses and households have to pay for their reconstruction can have important impacts on the reconstruction duration and causes a crowdingout effects on consumption and investment. Budget constraints (for households and businesses) may thus have macroeconomic consequences that need to be accounted for. To do so, we assume first the businesses pay their reconstruction by reducing the profits they redistribute to households. As a consequence, house hold income will decrease. Second, household budget constraints have been introduced. In this modeling, we assume that households can borrow to fund their reconstruction (without borrowing constraints), but that they then have to pay back over a 2-year period. To reimburse this additional debt, they reduce their consumption and investment. This factor introduces a consumer backward propagation in addition to the mechanisms described in Hallegatte (2008).

\section{References}

Alexander LV et al. (2006) Global observed changes in daily climate extremes of temperature and precipitation. J Geophys Res 111:D05109. doi:10.1029/2005JD006290

Benson C, Clay E (2004) Understanding the economic and financial impact of natural disasters. The international bank for reconstruction and development, The World Bank, Washington D.C.

Brookshire DS, Chang SE, Cochrane H, Olson R, Rose A, Steenson J (1997) Direct and indirect economic losses for earthquake damage. Earthq Spectra 13:683-701 
Carter TR, Jones RN, Lu X, Bhadwal S, Conde C, Mearns LO, O'Neill BC, Rounsevell MDA, Zurek MB (2007) New assessment methods and the characterisation of future conditions. In: Parry ML, Canziani OF, Palutikof JP, van der Linden PJ, Hanson CE (eds) Climate change 2007: impacts, adaptation and vulnerability. Contribution of working group II to the fourth assessment report of the intergovernmental panel on climate change. Cambridge University Press, Cambridge, pp 133-171

Dartmouth Flood Observatory (2008) http://www.dartmouth.edu/ floods/Archives/index.html

Dessai S, Hulme M, Lempert R, Pielke R Jr (2009) Climate prediction: a limit to adaptation? In: Adapting to climate change: thresholds, values, governance. Cambridge University Press. Available at http://sciencepolicy.colorado.edu/admin/publication_files/resource-2626-2009.01.pdf

Duryog Nivaran (2005) South Asia disaster report 2005. http://www.duryognivaran.org/sa_ annualdisaster.php\#

Fankhauser S, Smith J, Tol R (1999) Weathering climate change: some simple rules to guide adaptation decisions. Ecol Econ 30

Government of Maharashtra (GoM) (2005) Maharashtra floods 2005: relief and rehabilitation. http://mdmu.maharashtra.gov.in/pdf/Flood/statusreport.pdf

Grossi P, Kunreuther H (2005) Catastrophe modeling: a new approach to managing risk. Huebner international series on risk, insurance and economic security. Springer, New York

Gupta K (2007) Urban flood resilience planning and management and lessons for the future: a case of study in Mumbai, India. Urban Water J 4(3):183-194

Hallegatte S (2008) An adaptive regional input-output model and its application to the assessment of the economic cost of Katrina. Risk Anal 28(3). doi:10.1111/j.1539-6924.2008.01046

Hallegatte S (2009) Strategies to adapt to an uncertain climate change. Glob Environ Change 19:240247

Hallegatte S, Dumas P (2008a) Can natural disasters have positive consequences? Investigating the role of embodied technical change. Ecol Econ 68(3):777-786

Hallegatte S, Ghil M (2008b) Natural disasters impacting a macroeconomic model with endogenous dynamics. Ecol Econ 68(1-2):582-592

Hallegatte S, Hourcade J-C, Dumas P (2007) Why economic dynamics matter in assessing climate change damages: illustration on extreme events. Ecol Econ 62(2):330-340

Hallegatte S, Henriet F, Corfee-Morlot J (2011a) The economics of climate change impacts and policy benefits at city scale: a conceptual framework. Clim Change. doi:10.1007/s10584-010-9976-5

Hallegatte S, Ranger N, Mestre O, Dumas P, Corfee-Morlot J, Herweijer C, Muir-Wood R (2011b) Assessing climate change impacts, sea level rise and storm surge risk in port cities: a case study on Copenhagen. Clim Change. doi:10.1007/s10584-010-9978-3

Hanson S, Nicholls R, Ranger N, Hallegatte S, Corfee-Morlot J, Herweijer C, Chateau J (2011) A global ranking of port cities with high exposure to climate extremes. Clim Change. doi: 10.1007/s10584-010-9977-4

IPCC (2007) Climate Change 2007: the physical science basis. In: Solomon S, Qin D, Manning M, Chen Z, Marquis M, Averyt KB, Tignor M, Miller HL (eds) Contribution of working group I to the fourth assessment report of the intergovernmental panel on climate change. Cambridge University Press, Cambridge, p 996

Jenamani RK (2006) Observational/Forecasting aspects of the meteorological event that caused a record highest rainfall in Mumbai. Curr Sci 90(10):1344-1362

Jones RG, Noguer M, Hassell DC, Hudson D, Wilson SS, Jenkins GJ, Mitchell JFB (2004) Generating high resolution climate change scenarios using PRECIS. Met Office Hadley Centre, Exeter, p 40

Kumar KR, Sahai AK, Kumar KK, Patwardhan SK, Mishra PK, Revadekar JV, Kamala K, Pant GB (2006) High-resolution climate change scenarios for India for the 21st century. Curr Sci 90(3)

Lempert RJ, Collins MT (2007) Managing the risk of uncertain threshold responses: comparison of robust, optimum, and precautionary approaches. Risk Anal 27(4):1009-1026

Lindell MK, Prater CS (2003) Assessing community impacts of natural disasters. Nat Hazards Rev 4:176-185

Lubell J (2006) Housing displaced families, in rebuilding urban places after disasters, lessons from hurricane Katrina. In: Birch EL, Wachler SM (eds) University of Pennsylvania Press

MEERP (2007) Greater Mumbai disaster management action plan, risk assessment and response plan, vol. 1. Maharashtra Emergency Earthquake Rehabilitation Programme, Government of Maharashtra, Mumbai

Munich Re (2004) Megacities_-megarisks: trends and challenges for insurance and risk management. http://www.munichre.com/publications/302-04271_en.pdf 
Munich Re (2006) Topics geo: significant natural catastrophes in 2005. http://www.munichre.com/ app_resources/PDF/ts/geo_risks/04772_significant_natural_catastrophes_en.pdf

Municipal Corporation of Greater Mumbai (MCGM) (2008) http://www.mcgm.gov.in/

Nakicenovic N et al (2000) Special report on emissions scenarios: a special report of working group III of the intergovernmental panel on climate change. Cambridge University Press, Cambridge, U.K., 599 pp. Available online at: http://www.grida.no/climate/ipcc/emission/index.htm

Pielke RA Jr, Pielke RA Sr (1997) Hurricanes, their nature and impacts on society. Wiley, New York

Pohit S (2000) Income and employment effects in Mumbai region: an input-output approach. In: Proceeding of the XIII international conference on input-output techniques, University of Macerata, Italy, 21-25 August 2000

Ranger N, Millner A, Dietz S, Fankhauser S, Lopez A, Ruta G (2010) Adaptation in the UK: a decision making process. Grantham Research Institute/CCCEP Policy Brief, London School of Economics and Political Science, London, UK

Revi A (2005) Climate change risk: an adaptation and mitigation agenda for Indian Cities. Environ Urban 20(1)

Sharma M, Gupta K (2006) Storm water flow modeling of Mithi River in Mumbai Catchment. In: 2nd international IWA conference on sewer operation and maintenance, SOM 06, October 2628, 2006. Vienna, Austria

Sharpley AN, Williams JR (eds) (1990a) EPIC erosion productivity impact calculator: 1. Model documentation. U.S. Department of Agriculture Technical Bulletin No. 1768

Sharpley AN, Williams JR (eds) (1990b) EPIC erosion productivity impact calculator: 2. User manual. U.S. Department of Agriculture Technical Bulletin No. 1768

Swiss Re (2006) Natural catastrophes and manmade disasters 2005: high earthquake casualties, new dimension in windstorm losses, Sigma Series No 2, 2006. http://www.swissre.com/resources/ e109a780455c56b897efbf80a45d76a0-Sigma2_2006_e.pdf

Tierney K (1997) Business impacts of the northridge earthquake. J Conting Crisis Manag 5:87-97

Wallis TWR, Griffiths JF (1995) An Assessment of the Weather Generator (WXGEN) used in the erosion productivity impact calculator. Agric For Meteorol 73:115-133

West CT, Lenze DG (1994) Modeling the regional impact of natural disasters and recovery: a general framework and an application to hurricane Andrew. Int Reg Sci Rev 17:121-150

Williams JR, Nicks AD, Arnold JG (1985) Simulator for water resources in rural basins. J Hydraul Eng 111(6):970-986 